\title{
The Selection of Logistics Suppliers under Cloud Manufacturing
}

\author{
Hui Wang ${ }^{1}$, Yuantao Song ${ }^{2}$, Shenhao $\mathrm{Tu}^{2}$ and Yijun $\mathrm{Li}^{1}$ \\ ${ }^{1}$ School of Management, Harbin Institute of Technology, Harbin, China \\ ${ }^{2}$ School of Engineering Science, University of Chinese Academy of Sciences, Beijing, China
}

\begin{abstract}
The selection of logistic supplier is the key factor for the company to promote the operation efficiency and reduce the cost in business. It is crucial for the company to choose proper logistics suppliers based on the specific rules. With the development of scientific and technological innovation, such as AI, Big data, Cloud manufacturing. Etc, which changes the operation mode of logistics. The article puts forward a new method entropy-Topsis model to evaluate the logistics suppliers based on the cloud manufacturing environment, which helps the cloud manufacturing quickly and accurately evaluate and select logistics suppliers.
\end{abstract}

Keywords-logistics supplier; cloud manufacturing; entropy-TOPSIS; selection model

\section{INTRODUCTION}

With the development of market economy, the specialization of the company becomes the mainstream trend. The companies pay more attention on core business in order to promote the particular advantage, and outsource the non-core business. The key factor for outsourcing the logistic business is to choose a proper logistic supplier, which makes the material in the company be operated properly and safely.

The domestic and foreign scholars have taken up some research on the selection of logistic supplier, while most of research is based on the traditional viewpoint. Sun $\mathrm{Lu}$ [5] demonstrates how to use the self-organizing data mining technology and TOPSIS method to build the logistics supplier selection model and use the model to evaluate and select logistics suppliers accurately. DONG Jing-feng[6] used cluster analysis to find alternative 3PL suppliers which can meet the customers' demand, then apply multi-objective decisionmaking with entropy weight to calculate the distance and nearness between alternative supplier and ideal point to evaluate the suppliers. Tu Miao[7] proposed a supplier selection model on the basis of AHP and built the hierarchical structure using AHP to build the supplier selection model.

Through many thesis researches the different kinds of model to selection the logistic suppliers, while to a certain extent, they consider the logistic supplier selection problem based on the traditional viewpoint. With fast improvement, of the cloud manufacturing, plays an important role in enterprise's product and management. There are few research focusing on the selection of logistics supplier under cloud manufacturing. Accordingly, we propose the new method entropy-Topsis based on cloud manufacturing to optimize the logistic supplier selection in new era.

\section{The CONCEPT OF LOGISTICS SERVER CONCERNING Cloud MANUfACTURING}

In the logistics supply chain under the cloud manufacturing, the participants are divided into three major categories: cloud manufacturing service platform, users and suppliers. Cloud manufacturing service platform provides enterprises with encapsulation of resource service layer, transforming into cloud services, acquiring and decomposing user's task requirements, and providing cloud services to users in an economic and reasonable way through search matching. Users are divided into business users and individual users. They play dual roles in the cloud manufacturing supply chain, one is the final receiver of the service, which put forwards the demand for manufacturing tasks. The other is a provider of related needs and information, which affects the design and delivery of manufacturing services. The supplier provides the necessary resources and capacity support for the delivery of cloud services.

Compared with the traditional logistics supplier selection under the circumstance with the information asymmetry due to the traditional procurement activities, users can pay close attention to the procurement directly to the supplier. The traditional coordination of upstream supplier procurement activities only by virtue of experience and transaction history to select suppliers. In cloud manufacturing environment based on the concept of cloud manufacturing, the aim is to provide users with the service of the whole life cycle of the product manufacturing process. When choosing a supplier, manufactures can not only understand the supplier's production capacity and equipment utilization status, but also understand the utilization of equipment and resources in other links of supply chain in real time through cloud manufacturing service platform. Users choose suppliers and allocate orders reasonably, so that the whole production process of the supply chain can be continuously carried out, so as to achieve rational allocation of limited resources under the global perspective and improve the effectiveness of the entire supply chain and user satisfaction.

\section{The Selection Index System of Logistics SERVICE Provider BASED ON Cloud MANUfACtURING}

In this paper, a set of third party logistics evaluation system based on cloud manufacturing is set up, and the specific index system is as follows: 


\section{A. Capability Index}

The strength index generally evaluates the comprehensive strength of the logistic supplier and can be divided into following three parts:

1) Quantity of logistics equipment: It includes vehicle ownership, automated warehouse and modern logistics facilities. Because for different logistics companies, the ownership of all kinds of equipment is not comparable, so it can be expressed by the net asset value of all enterprises.

2) Market share: That is, the sales of a service provided by a third party logistics enterprise within a certain time accounts for the percentage of the same service in the industry.

\section{B. Service Indicators}

It is mainly measured by the punctual rate, the accuracy of the job, the completion rate of the task and the time of the customer complaint.

1) The rate of punctuality: The percentage of delivery, delivery, or delivery on time for a logistics company in a scheduled time.

2) Task completion rate: The number of logistics tasks required by a logistics company in a certain period of time accounts for the percentage of the number of total logistics tasks.

\section{Price Index}

The price index mainly refers to the determination and standard of the cost, considering whether the cost is reasonable and whether it meets the cost requirements of the enterprise. It is mainly reflected in the cost of logistics enterprises. So service price is a key factor for the selection of third party logistics suppliers, which is mainly reflected by the logistics cost.

\section{Index of Logistics Suppliers under the Cloud Manufacturing Platform}

1) Cloud service capability: Under the cloud manufacture platform, the logistics suppliers' ability to deal with and coordinate large-scale transportation tasks is crucial. The cloud service capability includes whether the logistics suppliers can handle large-scale concurrent demand orders and plan the transportation of logistics under large-scale orders.

2) Real-time residual quantity: Real-time residual quantity represents the volume of tasks that logistics providers can handle in real time under the cloud manufacturing platform, reflecting the maximum processing capability of each vendor's platform in real time. The Index evaluation table of logistics suppliers can be shown as follow:
TABLE I. INDEX EVALUATION TABLE OF LOGISTICS SUPPLIERS

\begin{tabular}{|l|l|l|}
\hline \multirow{4}{*}{$\begin{array}{l}\text { Evaluation } \\
\text { system of }\end{array}$} & strength index & $\begin{array}{l}\text { Quantity of logistics } \\
\text { equipment }\end{array}$ \\
\cline { 2 - 3 } $\begin{array}{l}\text { logistics } \\
\text { supplier index } \\
\text { under cloud }\end{array}$ & service indicators & Market share \\
\cline { 2 - 3 } & Price index & Task completion rate \\
\cline { 2 - 3 } & $\begin{array}{l}\text { Index of logistics } \\
\text { suppliers under the cloud } \\
\text { manufacturing platform }\end{array}$ & Cloud service capability \\
\cline { 3 - 3 } & & Real-time residual quantity \\
\hline
\end{tabular}

\section{Model OVERVIEW}

\section{A. The Overview of the Entropy-Topsis Method}

According to the 7 main indicators selected by logistics providers before, based on the premise of cloud manufacturing, this paper first scores the logistics providers, and then selects every time different logistics providers based on cloud manufacturing platform. In this paper, the -TOPSIS model of entropy value method is established, and the comprehensive evaluation of logistics suppliers is carried out.

First of all, this paper first uses entropy method to find the information entropy of each index. Information entropy is an index to measure the discrete values of elements in an index. For a certain index $\mathrm{K}$, the greater the difference between the index value $\mathrm{Ki}$, the greater the role of the index in the comprehensive evaluation plays. If the index value of a certain index is all equal, the index will not play a role in the comprehensive evaluation. First of all, we use entropy method to find out the difference degree of eight indicators. We take the difference degree of each index as the weight index of TOPSIS method, then use TOPSIS method to index the index and calculate the final score of each node. The steps of the algorithm are as follows:

Step1: Non negative processing of data; set the score matrix $A=\left[\begin{array}{c}X_{11}, X_{12} \ldots X_{1 n} \\ X_{21}, X_{22} \ldots X_{2 n} \\ \ldots \ldots \\ X_{m 1}, X_{m 2} \ldots X_{m n}\end{array}\right], X_{i j}$ means the jth value of ith company. The entropy method is based on the ratio of the total value of each plan to the same index value. Therefore, there is no dimensional effect and no standardized treatment is needed.

Step2: Calculating the entropy of jth index;

$$
\text { Set } P_{i j}=\frac{X_{i j}}{\sum_{i=1}^{n} X_{i j}} \mathrm{j}=1,2 \ldots \mathrm{m} \text {. }
$$

ej means the entropy of the jth index. $e_{j}=-k^{*} \sum_{i=1}^{n} P_{i j} \ln \left(P_{i j}\right)$ and $\mathrm{k}>0$, ej>0. Constant $\mathrm{k}$ is related to the total number of the sample, usually set $k=\frac{1}{\ln m}$ 
Step3: Define gi is the coefficient of variation of the jth index. The bigger gj the more important the index is. Set gj=1-ej.

Define $W_{j}=\frac{g_{j}}{\sum_{i=1}^{m} g_{j}}, j=1,2 \ldots m, w_{j}$ is the Weight calculated by the entropy method.

Step4: Standardization and index weighting; Standardize the matrix calculated by the step 1 , set $n_{i j}=\frac{x_{i j}}{\sqrt{\sum_{i=1}^{m} x_{i j}^{2}}}$ and $\mathrm{i}=1,2 \ldots \mathrm{m}, \mathrm{j}=1,2 \ldots, \mathrm{n}$. Then set $v_{i j}=W_{j} n_{i j}$, while $W_{j}$ is calculated by step 3 .

Step 5: Calculate the plus ideal solution and the minus solution.

$$
\begin{aligned}
& A^{+}=\left\{v_{1}^{+}, v_{2}^{+}, \ldots, v_{n}^{+}\right\}=\left\{\left(\max v_{i j} \mid j \in I\right)\right\} \\
& A^{-}=\left\{v_{1}^{-}, v_{2}^{-}, \ldots, v_{n}^{-}\right\}=\left\{\left(\max v_{i j} \mid j \in I\right)\right\}
\end{aligned}
$$

Step 6: Calculated the degree of the separation between the plus ideal solution and the minus solution.

$$
\begin{aligned}
& d_{i}^{+}=\sqrt{\sum_{j=1}^{n}\left(v_{i j}-v_{j}^{+}\right)^{2}} \\
& d_{i}^{-}=\sqrt{\sum_{j=1}^{n}\left(v_{i j}-v_{j}^{-}\right)^{2}}
\end{aligned}
$$

Step 7: Calculate the total score.

$$
r_{i}=\frac{d_{i}^{+}}{d_{i}^{+}+d_{i}^{-}}
$$

\section{CASE ANALYSIS}

The data from five logistics providers of the past ten years have been collected and shipped. The corresponding business data of the logistics providers are taken as raw data sources, and the data are standardized. The results are shown in Table ii..

TABLE II. INDEX EVALUATION TABLE OF LOGISTICS SUPPLIERS

\begin{tabular}{|c|c|c|c|c|c|}
\hline & S1 & S2 & S3 & S4 & S5 \\
\hline $\begin{array}{c}\text { Quantity of logistics } \\
\text { equipment }\end{array}$ & 0.81 & 1.16 & 0.45 & 0.73 & 0.72 \\
\hline Market share & 0.41 & 0.7 & 0.6 & 2.24 & 0.68 \\
\hline the rate of punctuality & 2.56 & 2.19 & 0.5 & 2.39 & 0.69 \\
\hline Task completion rate & 1.31 & 1.66 & 0.42 & 1.44 & 0.19 \\
\hline Price index & 0.4 & 0.27 & 1.41 & 1.68 & 1.37 \\
\hline $\begin{array}{c}\text { Cloud service } \\
\text { capability }\end{array}$ & 0.25 & 0.56 & 0.25 & 0.51 & 1.24 \\
\hline $\begin{array}{c}\text { Real-time residual } \\
\text { quantity }\end{array}$ & 0.58 & 1.6 & 1.53 & 0.75 & 0.41 \\
\hline
\end{tabular}

According to the entropy-TOPSIS method, the results are as follows:
TABLE III. RESULTS OF THE SUPPLIERS

\begin{tabular}{|l|l|}
\hline S5 & 0.040 \\
\hline S4 & 0.039 \\
\hline S1 & 0.033 \\
\hline S3 & 0.033 \\
\hline S2 & 0.030 \\
\hline
\end{tabular}

So, fifth suppliers are the best choice.

\section{CONCLUSION}

In this paper, the information entropy and the TOPSIS method are combined to establish a practical and objective evaluation method of logistics suppliers. This method can help enterprises choose the right logistics providers more conveniently, help enterprises integrate the outsourcing business into the value chain creation process, and make the enterprises have stronger core competitiveness.

\section{REFERENCES}

[1] Pokharel S., tha A. Perspectives in Reverse Logisics: a Review[J]. Resources, Conservation and Recycling,09(4): 175-182.

[2] Kahraman C, Cebeci U, Ulukan Z. Multi-criteria supplier selection using fuzzy AHP[J]. Logistics information management, 2003, 16(6): 382-394.

[3] Serafim O., Hshiung G. T. Compromise Solution by MCDM Methods : A Comparative Analysis of VIKOR and TOPSIS[J]. European Journal of Operational Research, 2004(15): 445-455.

[4] Ma J., Fan Z.P., Huang L. H.. A Subjective and Objective Integrated Approach to Determine Attributes Weights [J].European Journal of Operational Research, 199(2): 397-404.

[5] Sun Lu. Study on Logistics Supplier Selection Model Based on SODM-TOPSIS[J]. Logistics Technology, 2015,32(12):333-335

[6] DONG Jing- feng, WANG Gang, LV Min, et al. Evaluation model of third- party logistics suppliers selection based on entropy theory[J]. Computer Engineering and Applications, 2007, 43(22) : 194- 196.

[7] Tu Miao,Hu Xiaofeng, Li Jinling, Wen Yingjie, Study on Supplier Selection Model Using AHP[J]. Logistics Technology, 2014,04,229:232. 